\title{
The Formation of Nocturnal Rainfall Offshore from Convection over Western Kalimantan (Borneo) Island
}

\author{
Peiming WU, Manabu D. YAMANAKA \\ Institute of Observational Research for Global Change, JAMSTEC, Yokosuka, Japan \\ and \\ Jun MATSUMOTO \\ Institute of Observational Research for Global Change, JAMSTEC, Yokosuka, Japan \\ Graduate School of Urban Environmental Sciences, Tokyo Metropolitan University
}

(Manuscript received 31 August 2007, in final form 4 June 2008)

\begin{abstract}
This study investigates the diurnal variation of convection over western Kalimantan (Borneo) Island and the adjacent seas through analysis of results from surface meteorological observations, satellite observations of convection and precipitation, and numerical experiments with a mesoscale model. Precipitation measurements from the TRMM satellite indicated that rainfall occurs mostly in the afternoon and evening along the coast of the island, and at night and in the early morning over the plains in the central regions of the island and over the sea adjacent to the coast. Results from surface meteorological observations showed that intense shortwave radiation is observed on the western coast at Siantan on most days, even on days with heavy rain. Consequently, sea breezes are evident in the afternoon, whereas land breezes prevail in the early morning. Occasionally, a strong offshore flow is observed by the QuikSCAT satellite over the sea adjacent to the western coast of the island in the early morning, with calm surface winds on the coastal land.

Climate modeling studies for a 1-month period during the region's rainy season successfully replicated the main features of the observed regional distribution, diurnal variation of surface winds and convection over the western coast of the island and the adjacent seas. The results showed that convections develop across a wide area along the coast of the island at similar times in the late afternoon with the penetration of the sea breeze. The convections cause a rapid drop in temperature in the lower atmosphere, which produces a temperature contrast between the land and the sea, with lower temperatures occurring over the island. In response to the temperature differences, a strong offshore flow occurs over the sea adjacent to the western coast during nighttime, which creates an intensive wind convergence at the low-levels, and initiates convection offshore near the coast at late night and early morning. The results of this study suggest that the strong offshore flow derived principally from convections that develop earlier in the afternoon and evening over the island plays an important role in the formation of the nocturnal rainfall over the sea in the vicinity of western Kalimantan Island.
\end{abstract}

Corresponding author: Peiming Wu, Institute of Observational Research for Global Change, Japan Agency for Marine-Earth Science and Technology, Natsushima-cho 2-15, Yokosuka, Kanagawa 2370061, Japan

E-mail: pmwu@jamstec.go.jp

(C)2008, Meteorological Society of Japan

\section{Introduction}

Convective activity over the Maritime Continent region is generally more active than over other tropical regions, and latent heat released into the atmosphere in the region is one of the major energy sources driving global atmospheric circula- 
tions (e.g., Ramage 1968; Neale and Slingo 2003). This region is characterized by its low latitude location and complex land/ocean geography. Large mountainous islands, such as Sumatra, Kalimantan (Borneo), New Guinea and many other islands of various sizes are located in the region. The complicated topography and its induced circulations can significantly affect the formation and distribution of convection in the region.

Island/peninsula convection has been examined through observations and numerical experiments for tropical and subtropical regions both with and without significant island topography. Pielke (1974) successfully simulated the sea-land breeze circulations and their related diurnal convection over the Florida peninsula with a full-scale three-dimensional numerical hydrostatic model for the first time, showing that convergence resulting from thermally induced diurnal circulations controlled the location of the developing thunderstorm complexes. Results from the Hawaiian Rainband Project (HaRP) showed that the surface airflow and rainfall occurrences over the Hawaiian Islands are strongly modulated by the diurnal heating cycle (e.g., Chen and Nash 1994). Saito et al. (2003) studied the diurnally forced island convection in the absence of significant topography over the Tiwi Islands, north of the Australian continent during the Maritime Continent Thunderstorm Experiment (MCTEX). They noted that the intensity of convection over the tropical island is influenced significantly by the island-scale circulation.

The diurnal variation of convective activity over the Maritime Continent region has been investigated through analysis of infrared (IR) observations from Geostationary Meteorological Satellite (GMS). Convection over large islands exhibits a late afternoon and evening maximum. Over sea areas in the vicinity of large islands, maximum convective activity generally occurs in the morning (Murakami 1983; Nitta and Sekine 1994; Ohsawa et al. 2001).

The Precipitation Radar (PR) onboard the Tropical Rainfall Measuring Mission (TRMM) satellite has been in operation since December 1997, providing invaluable data on spatial and temporal variation of tropical rainfall around the globe. The TRMM measurements fill a significant gap in the available observations by enabling determination of the frequency distributions of rainfall intensity and regional coverage over the tropical oceans and rain forest regions. Studies on the regional distribution of rainfall in the Maritime Continent region using the TRMM precipitation data indicated that annual rainfall amounts over the sea adjacent to western Sumatra, most areas of Kalimantan Island and New Guinea Island are among the highest on Earth, with mean annual values in these regions typically over $4000 \mathrm{~mm}$. Convective rainfall predominates in the afternoon to evening over the land area, whereas compound stratiform and convective rain is predominant in the morning over the surrounding sea region (Mori et al. 2004). Ichikawa and Yasunari (2006) investigated the time-space characteristics of diurnal rainfall over Borneo (Kalimantan) Island and surrounding oceans using rainfall data from the TRMM Precipitation Radar. They showed that rainfall activity propagates to the leeward side of Borneo Island between midnight and morning in both the low-level easterly or westerly regimes over and around Borneo.

The afternoon and evening maximum of convection and rainfall typically observed over tropical islands results from development of the mixed layer and diurnal changes in boundary-layer flow driven by diurnal heating associated with the strong solar irradiance at low latitudes (Oki and Mushiake 1994; Mapes et al. 2003a; Wu et al. 2003). In contrast, the formation mechanism of nighttime and morning convection/rainfall in tropical regions is unclear, since observational data are often unavailable, especially over the vast tropical ocean and rain forest areas.

Houze et al. (1981) observed an extremely regular genesis of nocturnal convection near the coast in northwestern Borneo and propagating offshore in the morning in an analysis of radar observations during the Winter Monsoon Experiment (WMONEX). Land breeze interaction with the prevailing winter monsoon flow was documented as producing the offshore convection at night and early morning off the northern coasts of Borneo (Kalimantan) Island. However, because nighttime radiative cooling produces temperature changes only in a shallow layer near the land surface, and the cooling ground creates a stable stratified boundary layer that inhibits vertical motion, the associated land breezes tend to be much shallower and weaker than sea breezes. As Mapes et al. (2003b) pointed out, at the northern coasts of Borneo the land breeze component from the southeast is orthogonal to the prevailing northeasterly boreal winter monsoon flow, not in convergent opposition to it. Moreover, Ohsawa et al. (2001) noted that the 
morning maximum of convection occurs over the sea in northwestern Borneo even in summer, when the prevailing wind is in the same direction as the land breeze. Thus, it is questionable whether the conceptual model of a land breeze converging with prevailing flow is an adequate interpretation for the formation of nocturnal convection in coastal areas of the tropics.

Over coastal seas bordering land areas with significant topography, topographically-induced local circulation may have an effect on convective activity. Mapes et al. (2003b) used satellite data and a numerical model to analyze the mesoscale convective systems moving outward from the Andes over the tropical Pacific Ocean. They showed that the land breeze mechanism is unlikely for the heavy nocturnal offshore convection west of Ecuador in South America. They suggested that the diurnal propagation of the mesoscale convective systems over the tropical Pacific Ocean west of Ecuador was controlled by gravity waves driven by diurnal heating of the elevated land surface of the Andes. As will be shown in Section 2, precipitation measurements from the TRMM satellite indicate that rainfall occurs mostly over the coastal land of Kalimantan Island in the afternoon and evening, and over the seas adjacent to the coast at night and in the early morning. The formation mechanism of the nocturnal convection over the sea west of Kalimantan Island is possibly similar to that west of Ecuador. However, while the high Andes mountains are close to the coast, only gently undulating hills are located in the western area of Kalimantan Island, and the mountains in the central area of the island are located about $500 \mathrm{~km}$ away from the west coast. Moreover, rainfall over the sea adjacent to the western coast of Kalimantan Island is concentrated in a narrow area located much closer to the shore (about $100 \mathrm{~km}$ ) than that over the sea to the west of Ecuador. Thus, the formation mechanism of the nocturnal offshore convection over the sea west of Kalimantan remains unclear.

Understanding the formation mechanism of the nocturnal convection over the Maritime Continent region is essential for improved predictability of rainfall in weather forecasts and improved global climate predictions. The purpose of this study is to clarify the diurnal cycle of convective activity over western Kalimantan (Borneo) Island and the adjacent seas, and to gain improved understanding of the formation mechanism of the nocturnal convection over the sea west of the island through analysis results from surface meteorological observations and numerical experiments with a nonhydrostatic, cloud-system resolving numerical model.

\section{Satellite observations of regional distribution and diurnal variation of convection and rainfall in and around Kalimantan Island}

We examine the diurnal variation of rainfall over Kalimantan Island and the surrounding seas using the TRMM $2 \mathrm{~A} 25$ product distributed by the National Aeronautics and Space Administration (NASA), Goddard Distributed Active Archive Center (DAAC). The TRMM 2A25 PR near-surface rain data (version 5) (Iguchi et al. 2000) were averaged to a 0.1 degree grid square for each local time at each grid point. The annual mean nearsurface rain detected by the Precipitation Radar (PR) onboard the TRMM satellite for the 6-year period from 1998 to 2003 is displayed in Fig. 1. In the morning and early afternoon (0800-1400 LT), most areas of Kalimantan Island are nearly rainfree. During the late afternoon and early evening hours (1400-2000 LT), rainfall occurs mostly over the island along the coast and over the mountains of the island. During these times of day, a distinct, nearly rain-free zone is seen extending more than $100 \mathrm{~km}$ over the seas along the coast of the island. Subsequently, at nighttime (2000-0200 LT) rain occurs mainly over the plains in the central regions of the island and over the sea adjacent to the coast. Note that rainfall over the sea along the western coast of the island is concentrated in a narrow area located relatively close to the shore (about 100 $\mathrm{km}$ ), most of which occurs during the late night and early morning hours.

As western Kalimantan Island is located on the equator, air temperature varies little throughout the year. Rainfall occurs perennially in the region, although a period of relatively lower rainfall is observed during June to September (Bayong and Zadrach 1996). In this study, we examine the regional distribution and diurnal variation of convection over western Kalimantan Island and the surrounding seas during the rainy season of the region in April 2002.

A regular occurrence of afternoon and evening convection along the western coast of the island, and nighttime and morning convection over the sea west of the island is observed frequently in the infrared (IR) images from the GMS Satellite in the 

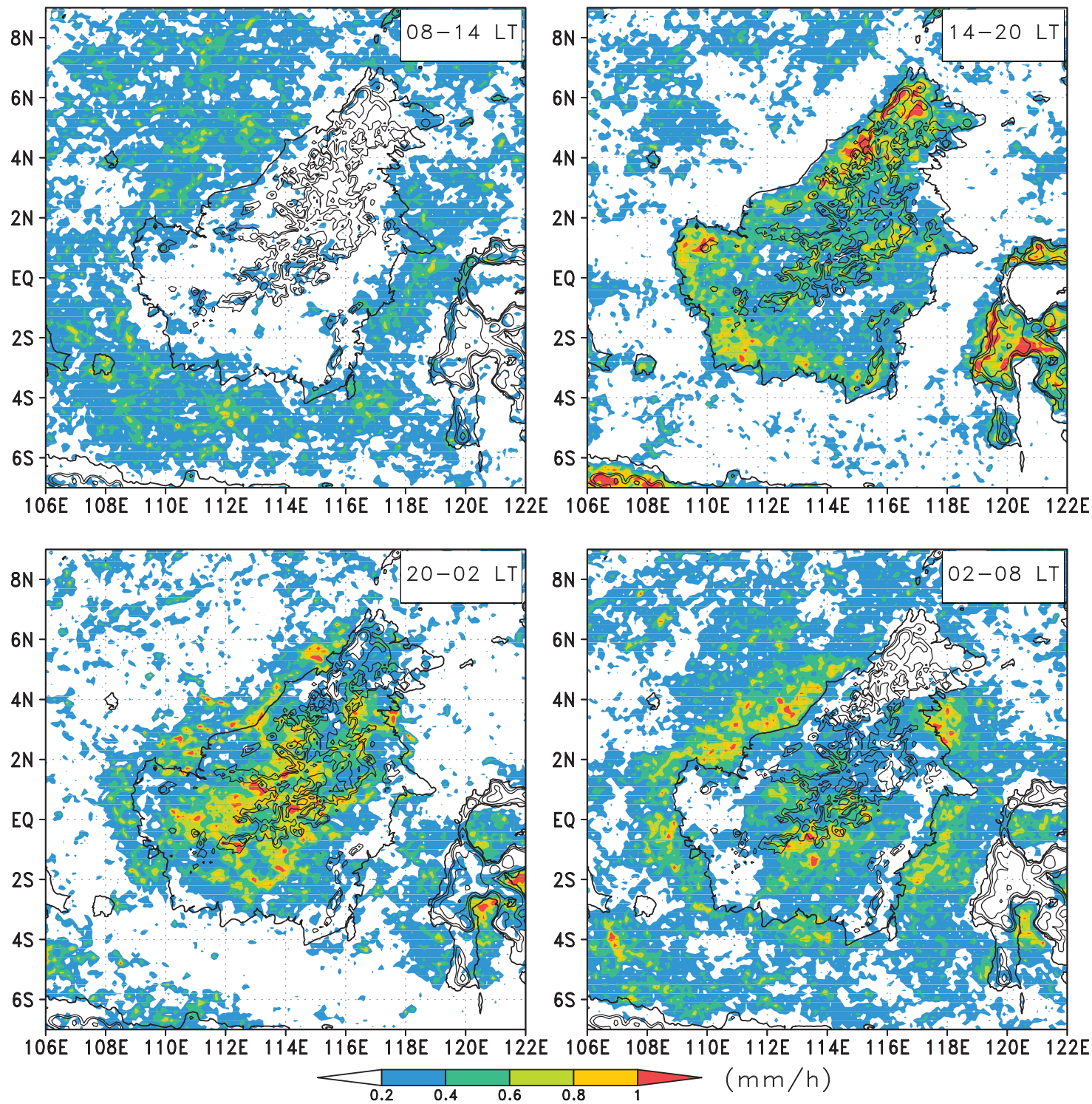

Fig. 1. The annual mean near-surface rain detected by the TRMM Precipitation Radar (PR) for the 6-year period from 1998 to 2003. Each panel shows the 6-hourly mean rainfall rate for the indicated time period. Solid contours show terrain elevation in 500-m intervals.

rainy season, especially when the prevailing winds are weak in the region. The typical diurnal cycle of convection in and around Kalimantan Island is shown in the four-day IR images from the Geostationary Meteorological Satellite GMS-5 for April 15 to 21, 2002 (Fig. 2). In the morning (by 1200 LT), most areas of Kalimantan Island are nearly cloudfree, as is apparent in the top row of panels. As the day progresses, convection is active along the coast over the land in the late afternoon (the second row of panels). The convection over the western coast migrates eastward to the central regions of the island during the evening and nighttime on 15 and 20 April. Convection over the sea offshore of the western coast occurs during the subsequent night and morning hours (the bottom row of panels). These features of the regional distribution and diurnal variation of convective activity in and around the island are similar to the climatological features of precipitation from the measurements of the TRMM satellite, as shown previously in Fig. 1. It is noteworthy that in all the cases shown in Fig. 

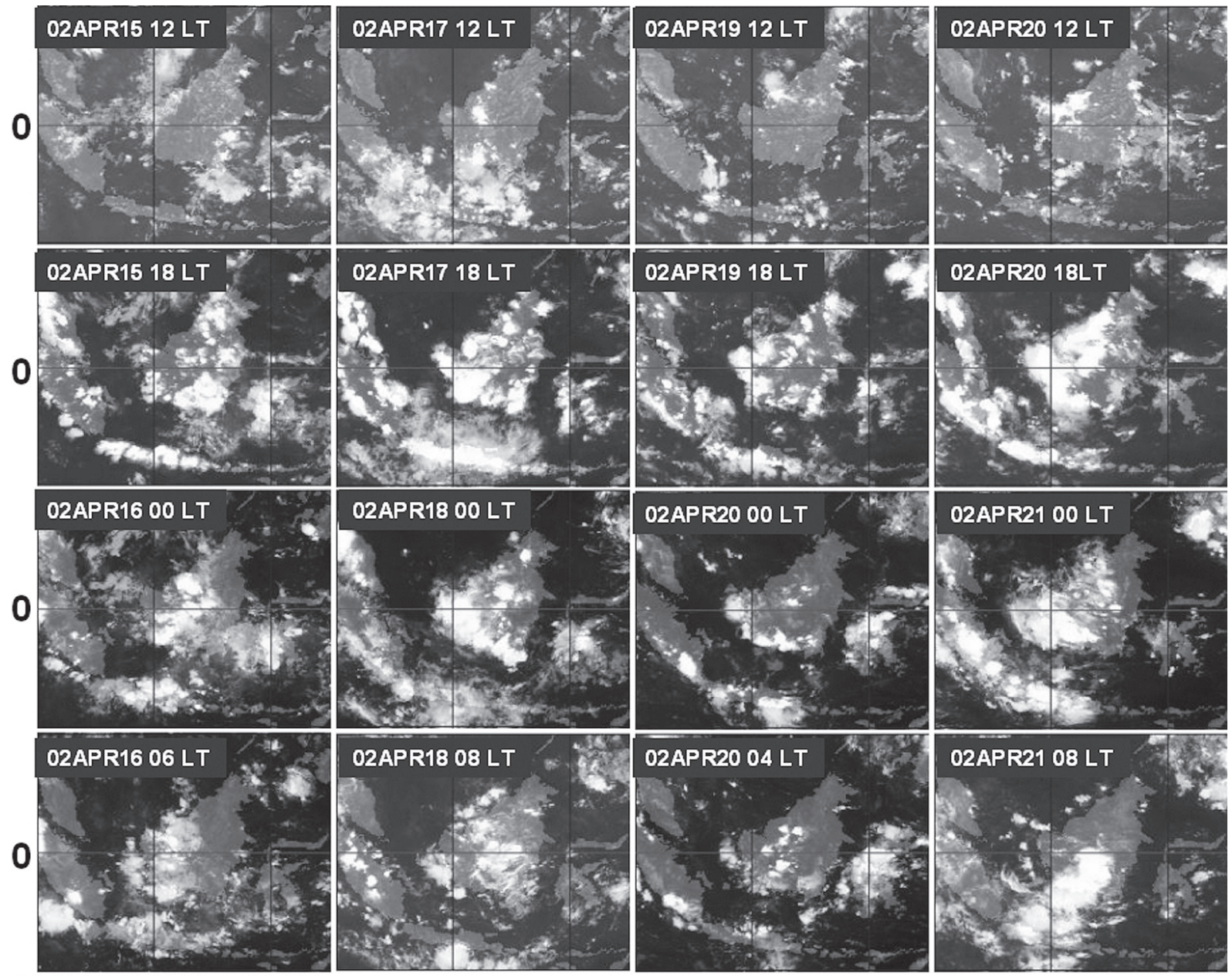

100E 110E 120E

Fig. 2. GMS satellite infrared (IR) images over Kalimantan Island and surroundings for April 15 to 21, 2002. These observations were acquired with the infrared channel of the GMS-5 satellite, which has a spatial resolution of $5 \mathrm{~km}$.

2, when convection over the sea offshore of the western coast occurs at late night and in the early morning of the next day, convective activity is very active across a wide area along the western coast of Kalimantan Island in the late afternoon and evening.

3. Diurnal changes of surface air temperature, winds and solar radiation observed at the western Kalimantan coast

We installed an Automatic Weather Station (MAWS 201, Vaisala) on the western coast of Kalimantan (Borneo) Island at Siantan (0.075N, 109.191E) (Fig. 3) in March 2002. Siantan is located in the plains about $1 \mathrm{~km}$ from the shore, with an elevation of about $2 \mathrm{~m}$ above sea level. Surface meteorological variables, including pressure, temperature, relative humidity, wind direction and speed, rainfall and global solar radiation were measured with a time interval of 60 minutes. In this section, we examine the variations of rainfall, solar radiation, air temperature and surface winds for April 2002.

The time series of rainfall, surface air temperature and global solar radiation at 1-hour intervals during 1 to 30 April 2002 are shown in Fig. 4. Rainfall occurs at Siantan on 23 days in April 2002, i.e., on about 2 out of 3 days, most of the rainfall occurs in a short time period of 1-2 hours in the late afternoon and evening. Meanwhile, daily maximum 


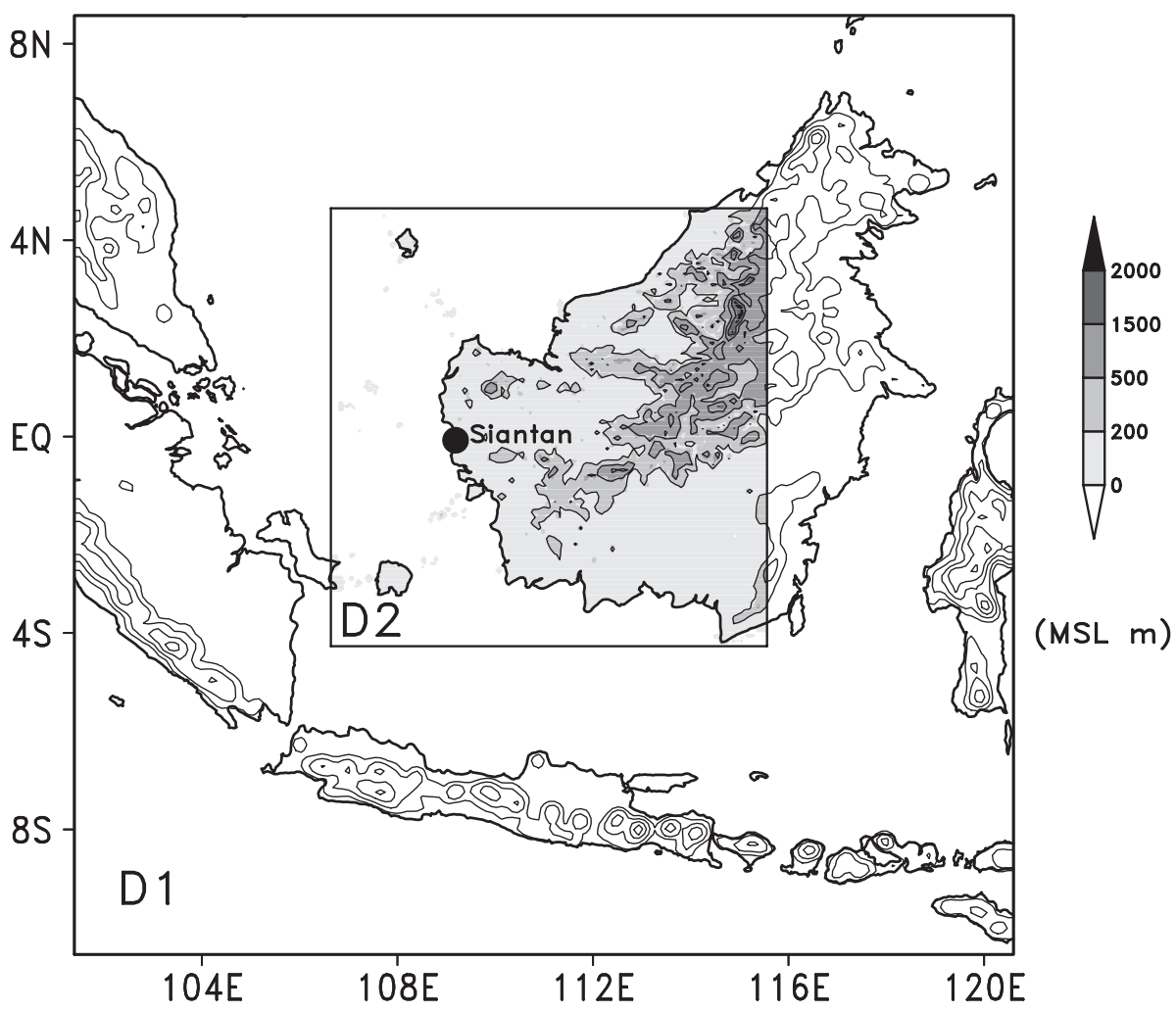

Fig. 3. The model domains and location of Siantan (black circle sign), where surface meteorological observations were conducted. D1 and D2 indicate areas of domain 1 and 2 in the model simulations, respectively. The shades of gray and contours denote terrain elevation.

hourly mean global solar radiation greater than $800 \mathrm{~W} \mathrm{~m}^{-2}$ is observed on most days, although occasionally daily maximum values of less than 700 $\mathrm{W} \mathrm{m}^{-2}$ are recorded. On days with rain, strong solar radiation is still observed since rainfall occurs mostly during the late afternoon and evening. On the other hand, the daily minimum surface air temperature is observed at 0600 LT on most days, and it increases rapidly from about 0700 LT, i.e., soon after sunrise. The daily maximum air temperature occurs at near local noon. Later, surface air temperature decreases with the penetration of the sea breeze, as described in the following paragraph. The monthly mean daily minimum and maximum surface air temperatures for April 2002 are 23.7 and $30.6^{\circ} \mathrm{C}$, respectively.

The observed surface wind vectors averaged over the 30 days of April 2002 at Siantan on the western coast are shown in Fig. 5. Land breezes (easterly) prevail during 0700-0900 LT in the morning, whereas sea breezes are evident during daytime (1100-1800 LT). The sea breezes diminish in the late afternoon and then almost dissipate by 2000 LT, about 1 hour after sunset, and the surface winds are almost calm during nighttime.

Sea and land breezes usually would be weak during the rainy season as clouds would prevent the land from heating up rapidly in the daytime and cooling off rapidly in the night. However, the situation in the coastal area of western Kalimantan Island is unique. As described previously, convection/rainfall in the region occurs mostly in the late afternoon and evening. The sky is almost cloudless over most areas of the island in the morning and early afternoon even on days with heavy rain. Strong solar radiation is observed on most days, with the result that sea breeze circulation occurs frequently in the afternoon on the western coast of the island (Figs. 4 and 5).

As shown previously in Fig. 2, convective activities along the coast over the land are very active in the late afternoon and evening on 15 April 2002. Convection over the sea near the western coast of the island is initiated at nighttime on 15 April, and 


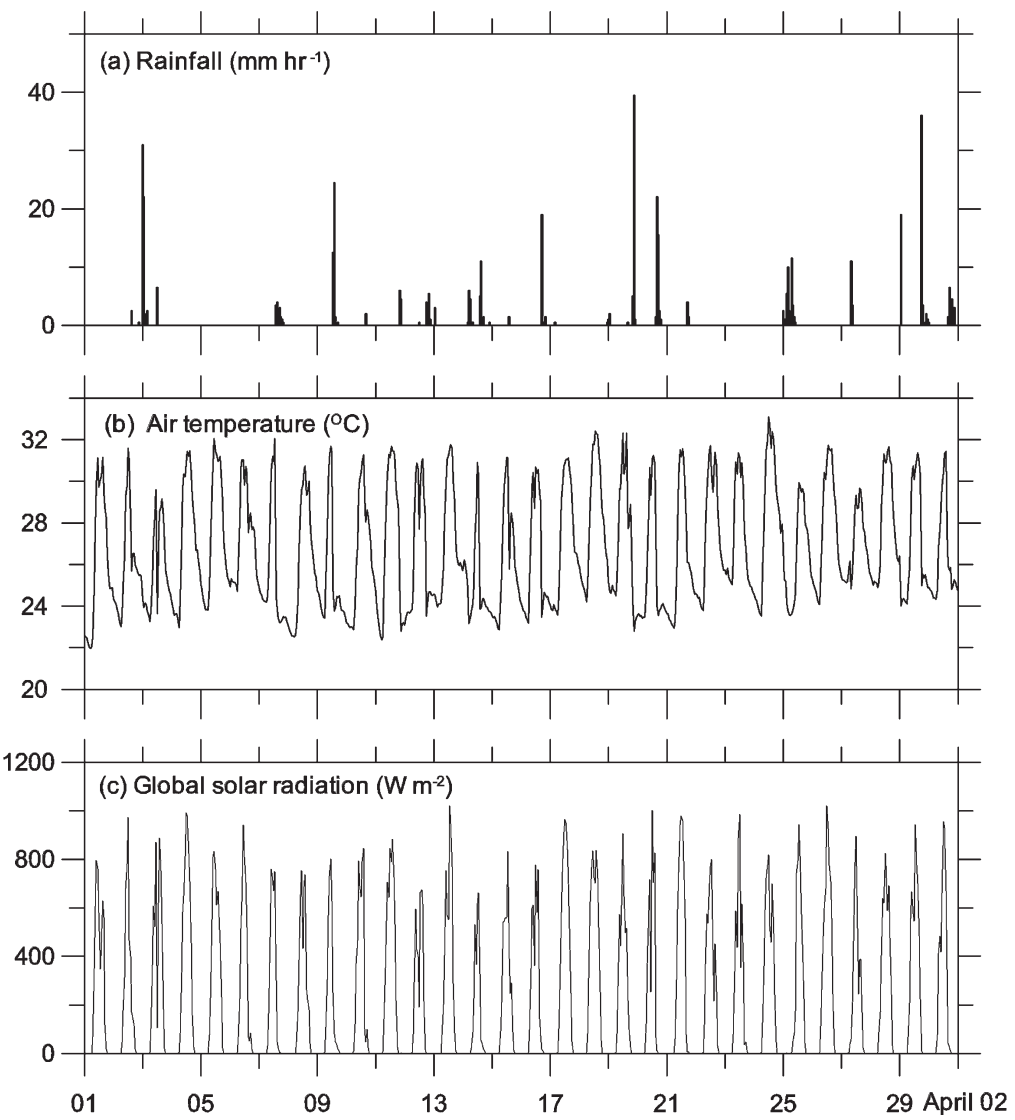

Fig. 4. Time-series of hourly rainfall, surface temperature and global solar radiation observed at Siantan at approximately $1.5 \mathrm{~m}$ above the ground for 1-30 April 2002.

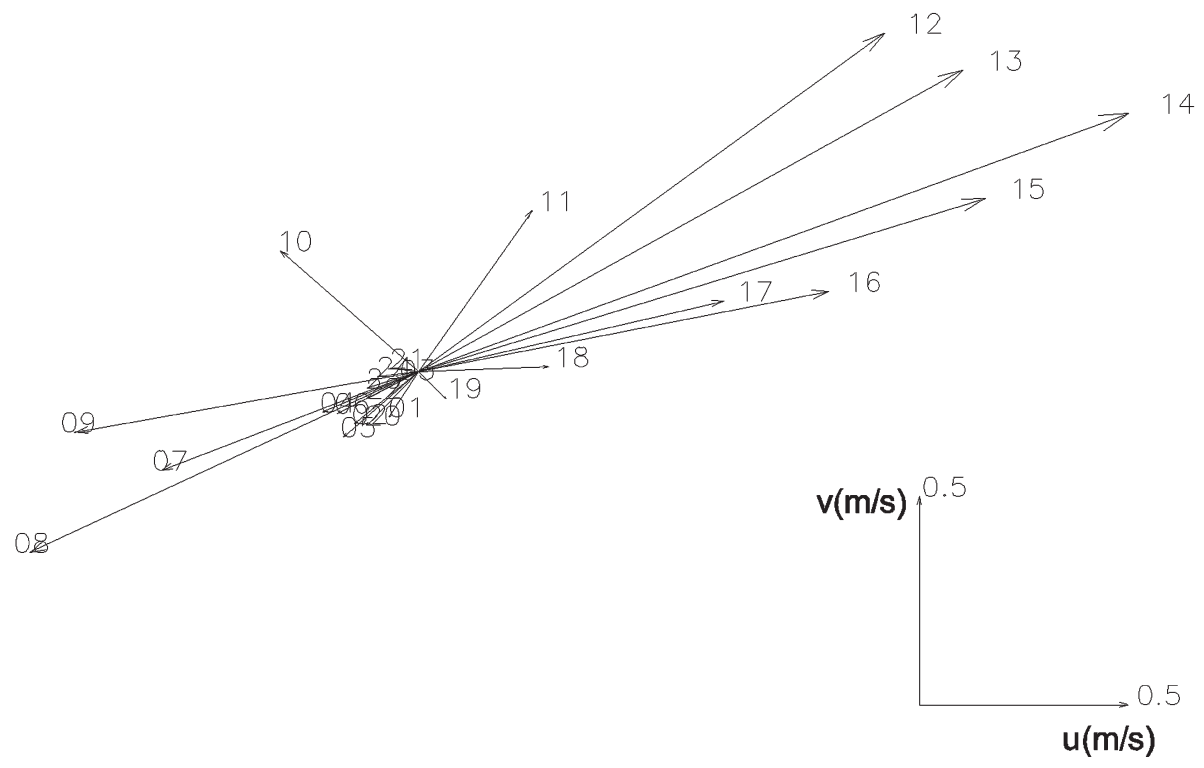

Fig. 5. The 1-month mean surface wind vectors observed at Siantan on the west coast at approximately 3.0 $\mathrm{m}$ above the ground surface for April 2002. The numbers in the Figure indicate the local time. 
persists to the morning of 16 April 2002. The sea surface winds measured by NASA's QuikSCAT Scatterometer onboard the QuikSCAT satellite at 2242 UTC on 15 (0542 LST on 16) April 2002 are displayed in Fig. 6. Sea surface winds are weak as wind speeds are less than $3 \mathrm{~m} \mathrm{~s}^{-1}$ over most areas of the South China Sea and the western area of the Karimata Straits. It is important to note that strong offshore (easterly) surface winds with speeds of $\sim 10 \mathrm{~m} \mathrm{~s}^{-1}$ are observed over the sea adjacent to the western coast of Kalimantan Island. On the other hand, meteorological observations on the western coast of the island at Siantan indicated that the surface winds are almost calm during the period from 0000 to 0600 LT on 16 April 2002 when the strong surface offshore winds occurs over the sea adjacent to the coast. Subsequently, offshore (northeasterly) winds with speeds of $0.9,1.7$ and 1.3 $\mathrm{m} \mathrm{s}^{-1}$ are observed on the western coast at Siantan at 0700,0800 and $0900 \mathrm{LT}$, respectively. It is thus evident that the strong offshore flow occurs over the sea adjacent to the western coast of the island at the late nighttime and in the early morning, with calm surface winds on the coastal land during the night.

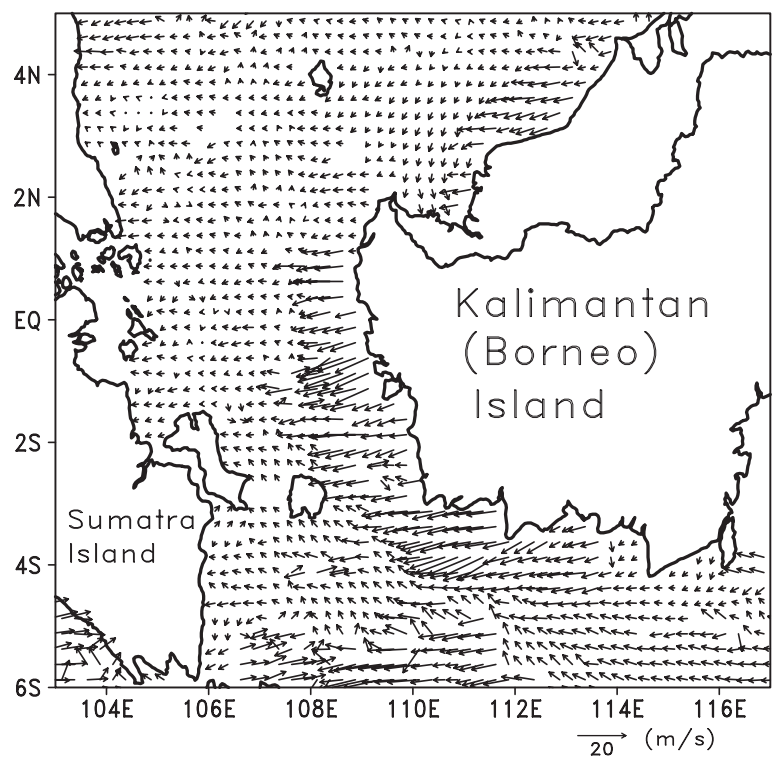

Fig. 6. Sea surface wind vectors measured by NASA's QuickSCAT Scatterometer onboard the QuikSCAT satellite at 2242 UTC on 15 (0542 LST on 16) April 2002.

\section{Numerical experiments and discussion}

\subsection{Model description}

The Pennsylvania State University/National Center for Atmospheric Research (PSU/NCAR) mesoscale model (MM5) (Dudhia 1993) was used to simulate the regional distribution, diurnal variation of convective activity and precipitation in and around western Kalimantan Island. The model domains are displayed in Fig. 3. The terrain elevation and land use data set from the USGS (U.S. Geological Survey) with a spatial resolution of 30 sec in longitude and latitude was used. The simulations were produced by using nested grids with grid intervals of 12 and $4 \mathrm{~km}$ for a 1-month climatological investigation, and a sensitivity study of the effect of convection on regional atmospheric circulation. Domain 1 (D1 in Fig. 3) is the mother domain, and domain 2 (D2) is two-way nested in domain 1 . The top of the model atmosphere is $100 \mathrm{hPa}$ with 31 vertical layers of the model atmosphere.

We used the Goddard cloud microphysics scheme, which is based on mixed-phase with graupel (Tao and Simpson 1993). Cumulus parameterization was not applied to the domains in the model. The MRF PBL planetary boundary layer scheme (Hong and Pan 1996), as implemented in the NCEP MRF (Medium Range Forecast) model, and Noah Land-Surface Model scheme were selected for the experiments. National Centers for Environmental Prediction (NCEP) global tropospheric analyses on $1.0 \times 1.0$ degree grids every 6 hours, including sea surface temperatures, were assumed for the initial and boundary conditions. The coarse and fine grids were integrated for a 1-month period (31 March to 30 April 2002) during the western Kalimantan Island's rainy season. Thus after initialization with the NCEP analyses, each domain has 1 day to spin up before the results are used for analysis.

\subsection{The diurnal variations of surface air tempera- ture, winds and rainfall from a 1-month model simulation}

In this study, to investigate the diurnal variation of convection and rainfall over western Kalimantan Island and the adjacent seas, climatological simulations were performed for the a 1-month period of April 2002 during the rainy season of the region. The mean surface air temperature and wind vectors from the model simulations at four different 
times of day for 1400, 2100, 0200 and 0700 LT are shown in Fig. 7. Surface air temperature at 1400 LT is about $31^{\circ} \mathrm{C}$ in most areas of the plains on the island. It decreases during the night, and the values at 0200 and 0700 LT in most areas of the plains on the island are about $24^{\circ} \mathrm{C}$. The model-simulated diurnal variations of the surface air temperature agree well with those observed on the western coast at Siantan, as shown previously in Fig. 4. In contrast to the land areas, air temperature over the surrounding seas remains relatively constant throughout the day, with a value of about $28^{\circ} \mathrm{C}$.
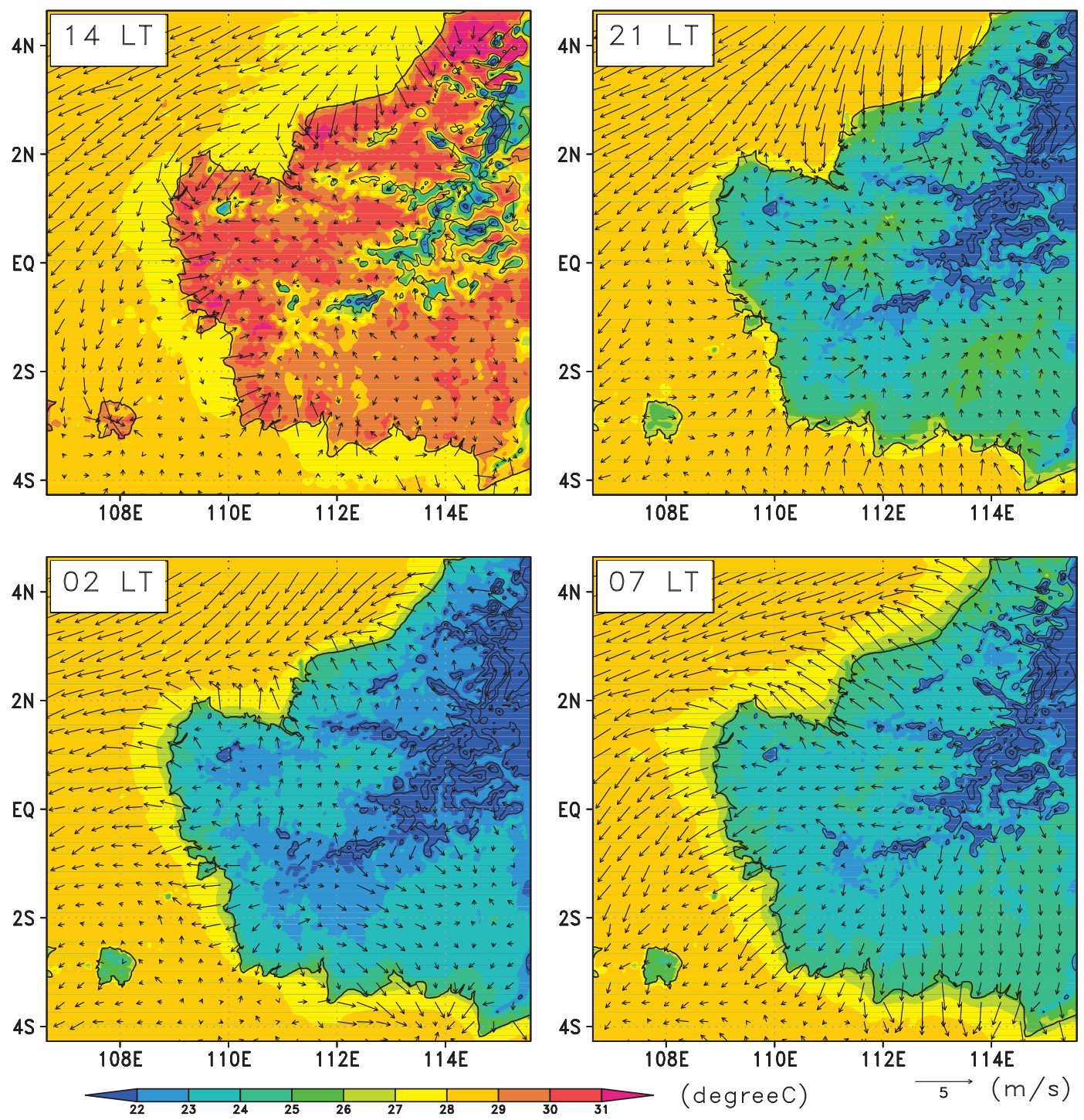

Fig. 7. The mean surface air temperature and wind vectors from domain 2 of the 1-month numerical experiments for 1400, 2100, 0200 and 0700 LT. The colors indicate the air temperature. Solid contours show terrain elevation in 500-m intervals. 
develops after 2100 LT and penetrates offshore about $100 \mathrm{~km}$ from the coast in the early morning. It was reported that in temperate regions, land breezes have been observed to occur later than 0300 LT, with a maximum wind speed of less than 4 $\mathrm{m} \mathrm{s}^{-1}$ at about 0600 LT in the morning, and the seaward penetration of the breezes reaches offshore only as far as $20-25 \mathrm{~km}$ from the coast (e.g., Hsu 1970; Meyer 1971). The time of occurrence of the land breeze over the sea adjacent to the western Kalimantan coast is thus much earlier and the horizontal extent of the breeze is father offshore than typical land breezes.

The regional distributions of precipitation and surface winds at four different times of day for 1200, 1800, 0000 and 0600 LT from the 1-month model simulation are shown in Fig. 8. The modelsimulated regional distribution and diurnal variation of precipitation agree with the observed variations of convection in the infrared images from the GMS satellite shown previously in Fig. 2. Most areas of Kalimantan Island are nearly rain-free during the morning hours (0600 and 1200 LT). In the afternoon (1800 LT), sea breezes are prominent
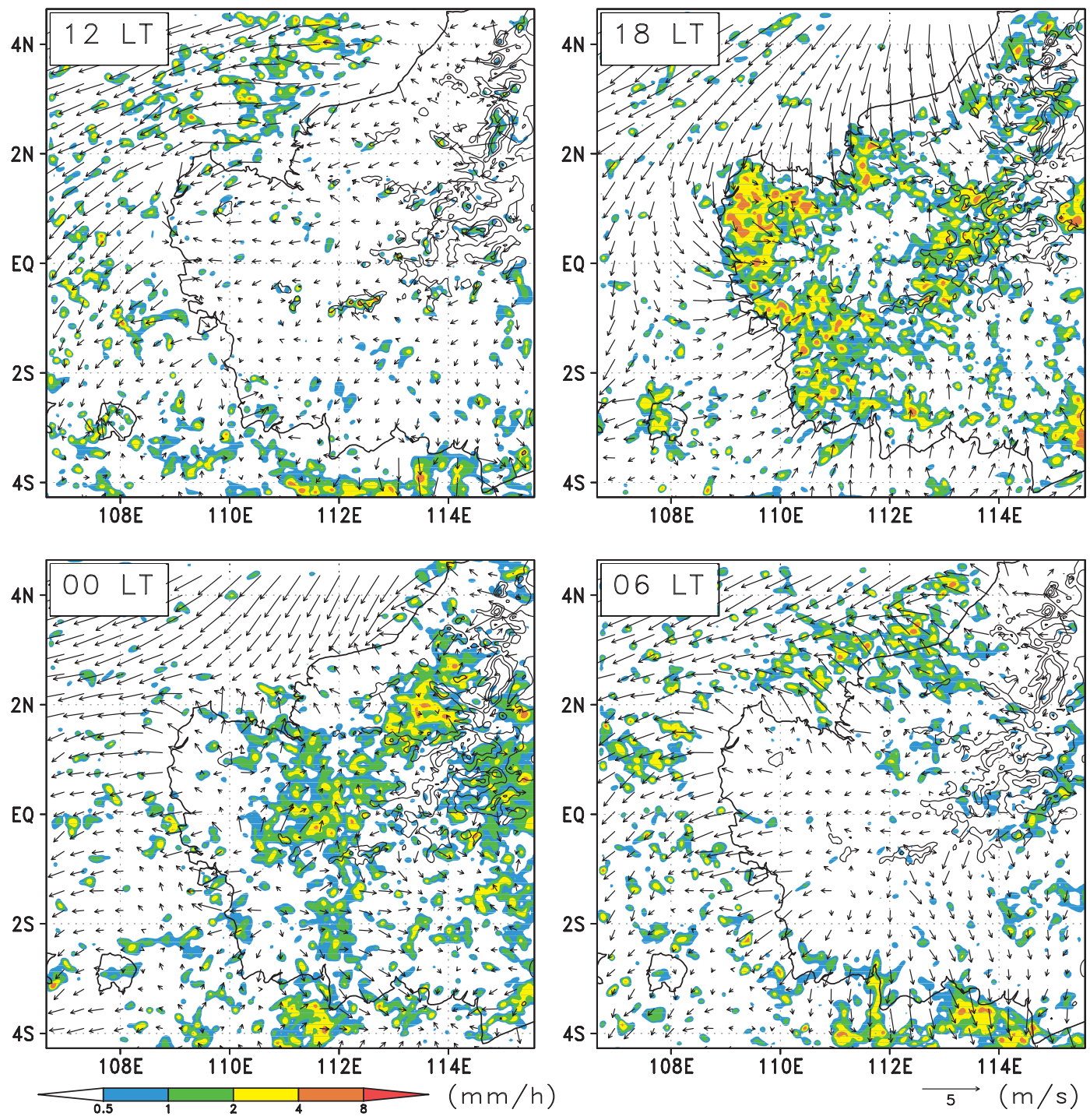

Fig. 8. The mean hourly rainfall rate and surface wind vectors from domain 2 (4-km mesh) of the 1-month numerical experiments for 1200, 1800, 0000 and 0600 LT. The colors indicate the hourly rainfall rate. Solid contours show terrain elevation in 500-m intervals. 
along the coast of the island, and rainfall occurs over the island along the coast with the penetration of the sea breeze. At this time, little rain is seen over the seas adjacent to the island along the coast. At nighttime (0000 LT), when rainfall along the coast of the island decreases, rainfall occurs mostly over the plains in the central regions of the island. Subsequently, in the early morning (0600 LT) while rainfall over the inlands of the island decreases, rain occurs mostly over the seas adjacent to coast of the island. These features of the regional distribution and diurnal variation of rainfall from the 1-month model simulations are similar to the climatological features of precipitation from the TRMM satellite measurements, as shown previously in Fig. 1.

\subsection{Sensitivity studies of effects of convection on the regional atmospheric circulation}

Sea breezes are common along tropical coasts because of the intense solar radiation and generally weak large-scale winds at low latitudes. Unlike sea breezes, land breezes occur less frequently and are generally weaker in velocity. Land breezes usually occur in the early morning, and penetrate offshore only as far as 20-25 km from the coast (Hsu 1970; Meyer 1971). However, as noted in Section 4.2, the surface winds from the 1-month model simulations showed that the land breezes over the sea along the western Kalimantan coast occur much earlier beginning before midnight and penetrate farther offshore to about $100 \mathrm{~km}$ from the coast in the early morning than typical land breezes. In this section, two simulations were performed, one with condensation of water vapor (control run) and a second without condensation (no-condensation model run) were performed to investigate the causes of the strong land breezes during the nighttime and early morning over the sea adjacent to the western coast of the island. The numerical simulations were applied to the region for 17-18 April 2002 (the calculation domains and grid increments are the same as the month-long experiments shown previously in Fig. 3). The coarse and fine grids were integrated for 72 hours start from 0000 UTC (0700 LT) 16 April 2002. As with the monthlong experiments, after initialization with the NCEP analyses each domain has 1 day to spin up before the results are used for analysis.

The surface winds and composite reflectivity simulated in the control run at three different times of day for 0900 and 1800 LT on 17 April, 0800 LT on 18 April are shown in Fig. 9. As in radar observations, the composite reflectivity displays the highest reflectivity of all elevation scans, which indicates the strength of convection. The results show that most areas of Kalimantan Island are nearly rain-free in the morning on 17 April 2002 (Fig. 9a). Convection occurs along the western coast of the island and over the mountainous areas of the island in the afternoon (Fig. 9b). Subsequently, the convections over the island dissipate, and convection is initiated over the sea along the western coast of the island near midnight on a) 09 LT 17 Apr $2002 \quad$ CTL

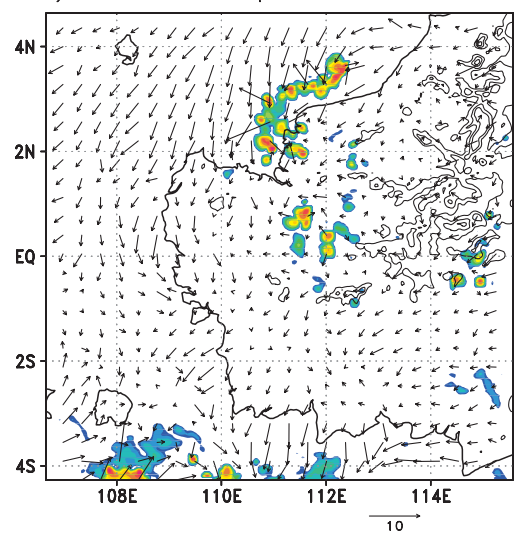

b) $18 \mathrm{LT} 17 \mathrm{Apr} 2002 \quad \mathrm{CTL}$

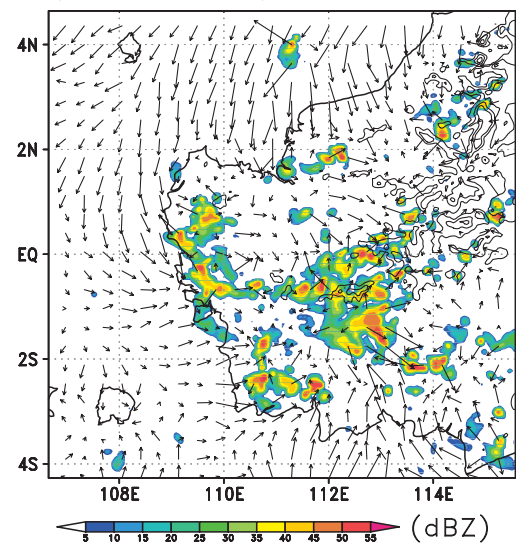

c) $08 \mathrm{LT} 18 \mathrm{Apr} 2002 \quad \mathrm{CTL}$

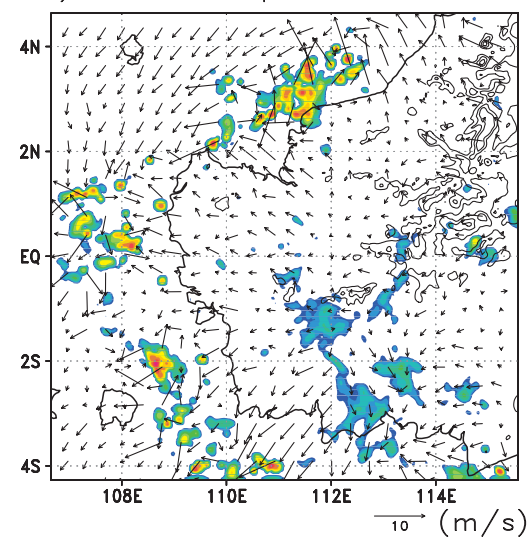

Fig. 9. The surface winds and composite reflectivity from domain 2 (4-km mesh) of the numerical experiments for a) 0900 and b) 1800 LT on 17 April, and c) 0800 LT on 18 April 2002. The colors show the composite reflectivity. Solid contours show terrain elevation in 500-m intervals. 
17 April, and persists to the morning on 18 April (Fig. 9c). The corresponding infrared (IR) images from the GMS Satellite (Fig. 2) indicate that in the late afternoon convective activity is very active along the western coast over the land, and over the mountains located in the inland areas of the island. Convection over the sea offshore of the western coast occurs in the subsequent late night on 17 April and early morning on 18 April. These results confirm that the numerical simulations successfully simulated the regional distribution and evolution of the convections over the island in the afternoon, and over the seas along the western coast at nighttime that are observed in the infrared images from the GMS satellite.

The surface air temperature and winds at three different times of day for 1400 LT on 17 April, 0000
LT and 0700 on 18 April are shown in Fig. 10 from the control run (the upper row of panels) and the no-condensation model run (the lower row of panels). In the control run, surface air temperature at $1400 \mathrm{LT}$ is about $31^{\circ} \mathrm{C}$ in most areas of the plains on the island. It decreases during night to early morning, and the values at 0000 and 0700 LT in most areas of the plains are about $24^{\circ} \mathrm{C}$. The model-simulated diurnal variations of the surface air temperature agree well with the diurnal variations observed on the western coast at Siantan, as shown in Fig. 4. On the other hand, the simulation results show that air temperature over the surrounding seas remains at a relatively constant value of about $28^{\circ} \mathrm{C}$ throughout the day.

It is important to note that the surface winds along the western coast at nighttime differ sub-

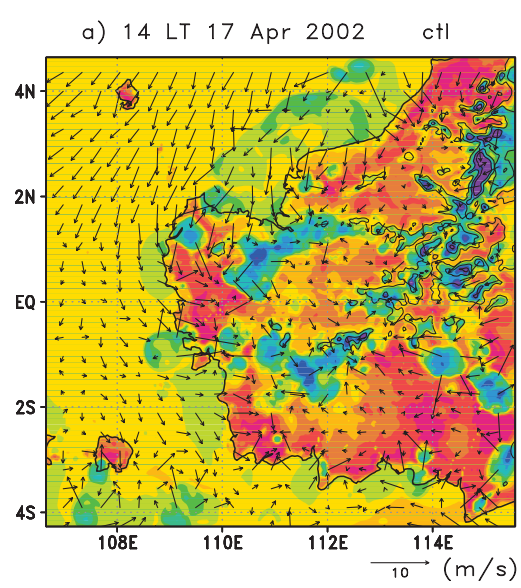

d) 14 LT 17 Apr 2002

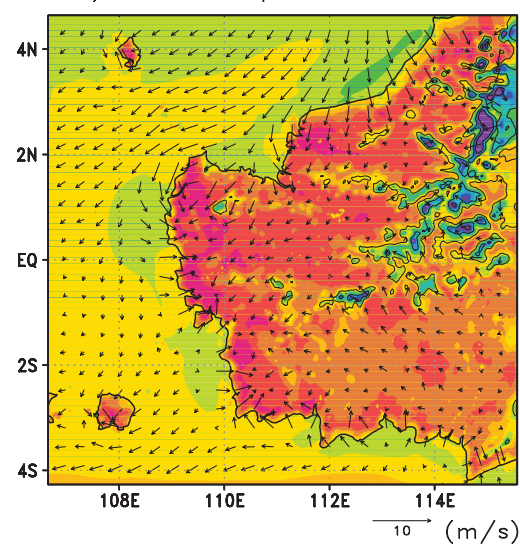

b) $00 \mathrm{LT} 18 \mathrm{Apr} 2002 \mathrm{ctl}$

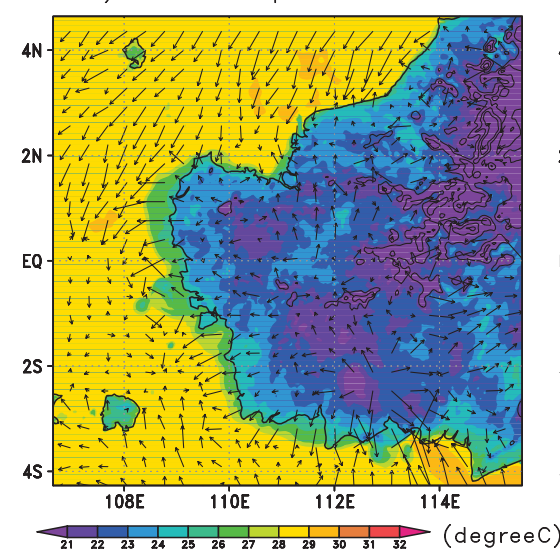

e) 00 LT 18 Apr $2002 \quad \mathrm{nc}$

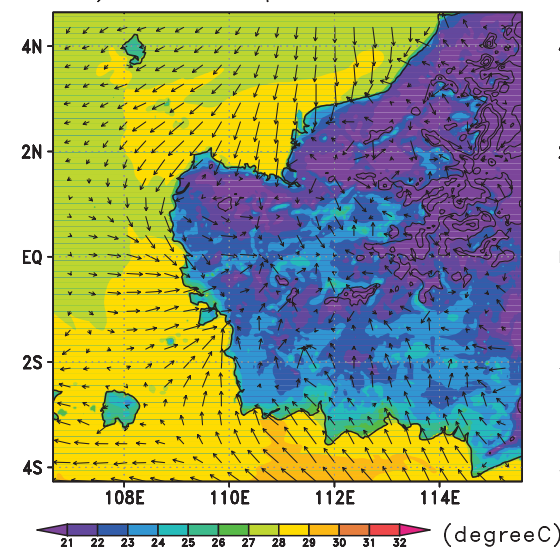

c) $07 \mathrm{LT} 18 \mathrm{Apr} 2002 \mathrm{ctl}$

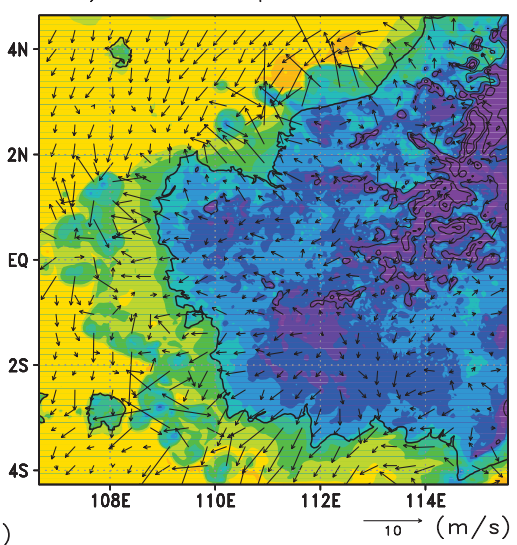

f) $07 \mathrm{LT} 18 \mathrm{Apr} 2002 \mathrm{nc}$

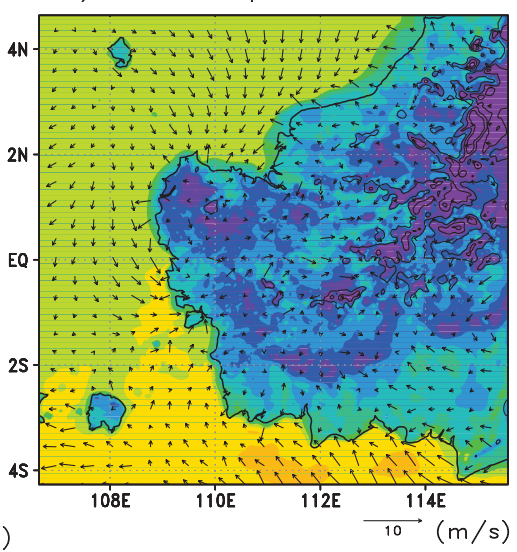

Fig. 10. A comparison of the results from (the upper row of panels) the control run and (the lower row of panels) the no-condensation model run of the numerical experiments for surface air temperatures and winds at 1400 LT on 17 April, 0000 and 0700 LT on 18 April 2002. The colors show the air temperature. Solid contours show terrain elevation in 500-m intervals. 
stantially between the control run and the nocondensation model run (Figs. 10b and e). In the control run, at 0000 LT a notable offshore flow (land breeze) with wind speeds of 7-8 $\mathrm{m} \mathrm{s}^{-1}$ occurs over the sea adjacent to the western coast of the island. In contrast, at this time land breeze does not occur in the surface winds from the no-condensation model run. It occurs only in the early morning along the immediate coastline, and weakens considerably a short distance offshore from the coast.

The cause of the differences of nighttime surface winds between the control run and the no-condensation model run is evident in the height-longitude cross-section of the potential temperature and the zonal wind along $0^{\circ}$ latitude at three different times of day in Fig. 11. In the afternoon (1400 LT), below $850 \mathrm{hPa}$ the potential temperatures over the land at the western coast are vertically rather uniform in both the control run and the no condensation model run because of development of the mixed layer, whereas temperatures above about 950 $\mathrm{hPa}$ over the sea decrease with height (Figs. 11a and d). Note that in the control run, the potential temperature below about $950 \mathrm{hPa}$ over the island decreases greatly in the evening (Fig. 11b), with the result that a temperature difference between the land and the sea is produced, and the greatest temperature gradient occurs over the sea adjacent to the western coast of the island. In response to the temperature differences, a strong offshore flow occurs beginning before midnight. In contrast, in the no-condensation model run decrease of the potential temperatures over the island does not occur in the evening (Fig. 11e). Meanwhile, the results a) $14 \mathrm{LT} 17 \mathrm{Apr} 2002 \mathrm{ctl}$

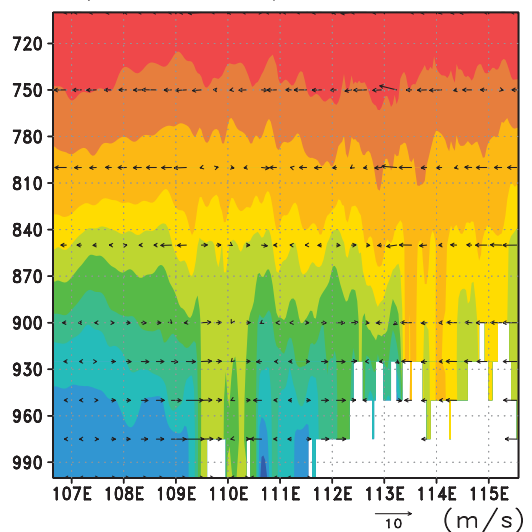

d) $14 \mathrm{LT} 17 \mathrm{Apr} 2002$

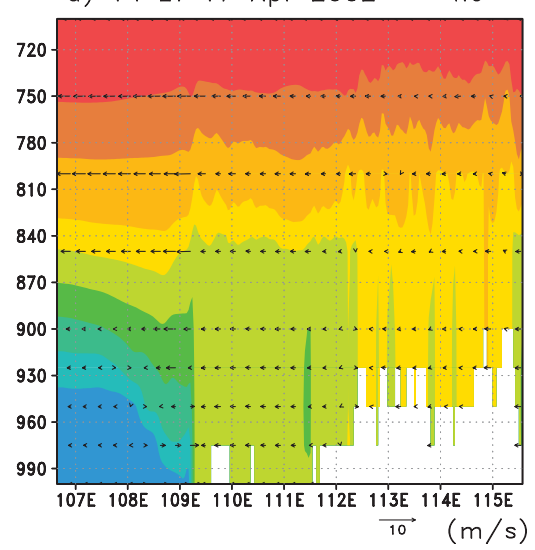

b) 23 LT 17 Apr $2002 \quad \mathrm{ctl}$

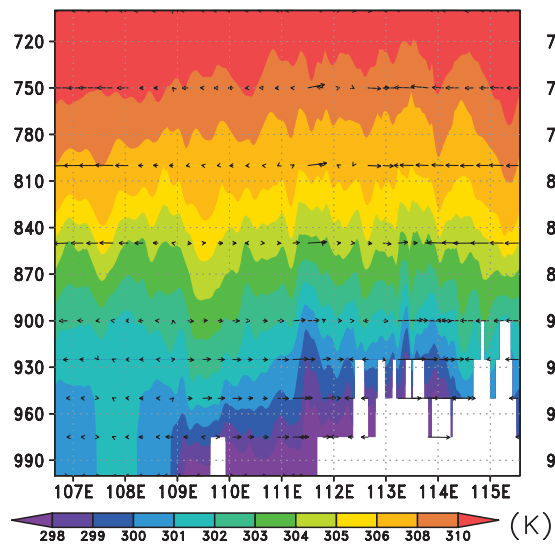

e) 23 LT $17 \mathrm{Apr} 2002 \mathrm{nc}$

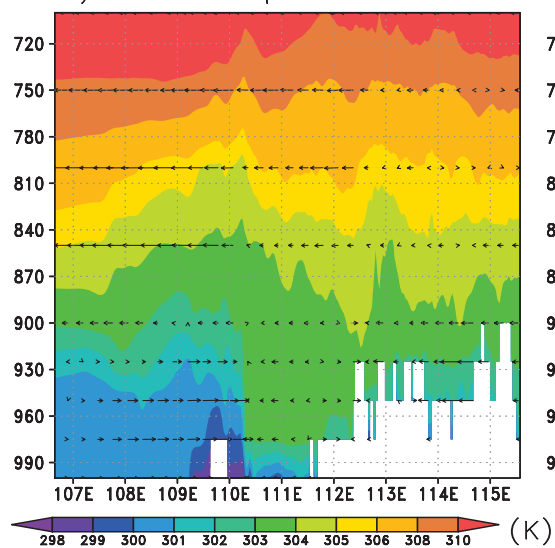

c) $07 \mathrm{LT} 18 \mathrm{Apr} 2002 \mathrm{ctl}$

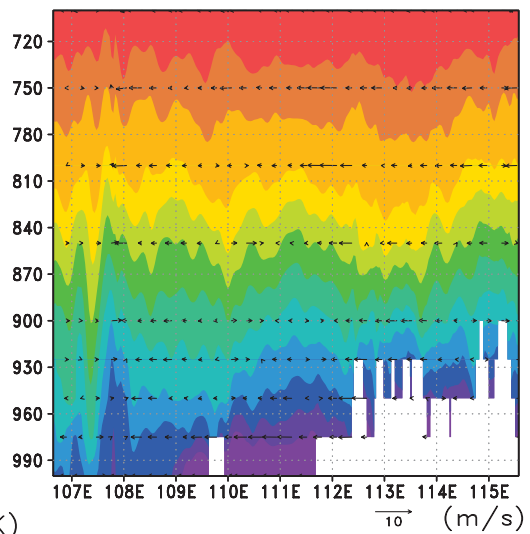

f) $07 \mathrm{LT} 18 \mathrm{Apr} 2002 \mathrm{nc}$

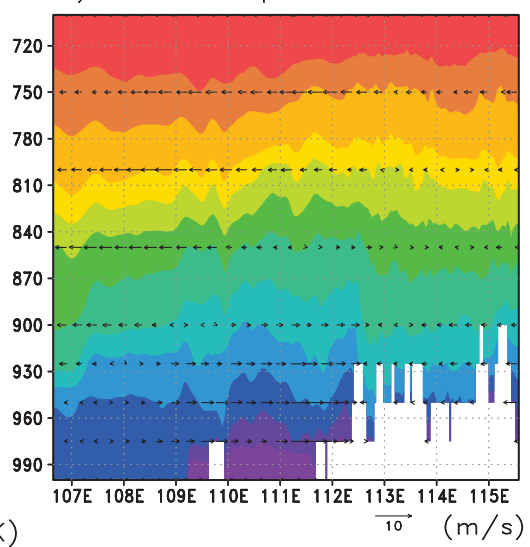

Fig. 11. A comparison of the results from (the upper row of panels) the control run and (the lower row of panels) the no-condensation model run of the numerical experiments for the height-longitude crosssection of the potential temperature and the zonal wind along $0^{\circ}$ latitude at 1400,2300 LT on 17 April and 0700 LT on 18 April 2002. The colors show the potential temperature, with topographic profiles in the pressure sections indicated in white. 
from the no-condensation model run show that the temperature differences remain before and after the sea breeze front over the island in the evening. As a result, the inland flow continues to penetrate farther inland because there is almost no Coriolis force to veer the inland flow in this near-equatorial area. The landward penetration of the sea breeze reaches a distance about 150 kilometers from the shore by midnight (2300 LT). Although this simulation result is not verified with observational data for Kalimantan Island, it is noteworthy that in some parts of the world, such as in Australia, the sea breeze has been observed to penetrate inland for distances of $200 \mathrm{~km}$ or more (Simpson 1994).

As air over land cools more rapidly during nighttime than air over sea, even in the no-condensation model run a temperature contrast between the land and the sea along the western Kalimantan coast occurs at night and in the early morning, with cooler air present over the island and relatively warmer air located over the sea. However, radiative cooling of the land produces only a weak land breeze in a narrow area along the immediate coastline during the time period from 0500 to 0700 LT (Figs. 10f and 11f). Past research results based on observations in northeast United States showed that a typical land breeze is a layer of cold air less than $100 \mathrm{~m}$ deep flowing out over the sea (Meyer 1971). On the other hand, Carbone et al. (1995) suggested that precipitation evaporation is the most frequent initiation mechanism of the nocturnal downslope offshore flow over the windward side of the island of Hawaii in an analysis of observational data during the Hawaiian Rainband Project (HaRP). The evaporative cooling in their study principally results from orographic rainfall over the island. Meanwhile, Feng and Chen (2001) used a numerical model to study the evolution of island airflow, thermodynamic fields, and clouds over the island of Hawaii at night. They suggested that rain evaporative cooling has pronounced influences on the depth, strength, and offshore extent of the katabatic flow. As mentioned above, in the control run of our experiments the decreases in the potential temperature over the island in the evening reach an altitude of about $950 \mathrm{hPa}(\sim 500 \mathrm{~m})$ (Fig. $11 \mathrm{~b}$ ), and the vertical extent of the offshore flow over the sea adjacent to the western coast is more than $950 \mathrm{hPa}$. The horizontal extent of the offshore flow in the early morning reaches about $100 \mathrm{~km}$ offshore from the coast. The time of occurrence of the decrease in the potential temperatures and the offshore flow over the sea adjacent to the island is much earlier, the depth, strength, vertical and horizontal extent of the offshore flow is greater than typical land breezes. The most likely cause of the decrease in temperature in the lower atmosphere is the precipitation evaporative cooling that may occur below the cloud base, as rainfall occurs frequently over the island along the coast in the late afternoon and evening. Moreover, the sensitivity experiments demonstrate that without condensation of water vapor, decrease in the potential temperatures in the lower atmosphere over the island in the evening and the resultant nighttime strong offshore flow over the sea adjacent to the island do not occur (Fig. 11e) as in the control run. These results suggest that the rapid drop in temperature in the lower atmosphere over the island along the western coast in the evening and nighttime, and the resultant nighttime offshore flow over the sea adjacent to the coast of the island are not caused primarily by nighttime radiative cooling of the land, but mainly by the decrease of temperature in the lower atmosphere associated with afternoon and evening convection over the island.

The observed and model-simulated wind speeds of the offshore flow for the single case study have a value of $\sim 10 \mathrm{~m} \mathrm{~s}^{-1}$ (Figs. 6 and 10b). In the surface winds from the 1-month simulations for April 2002 , offshore flow is seen over the sea along the western Kalimantan coast at night and in the early morning (Fig. 7). The offshore flow develops after 2100 LT and extends gradually toward the coastal waters. However, the offshore flow in the monthly averaged surface winds is weaker than that of the single case study. Convection over the island along the western coast occurs frequently in the late afternoon and evening (Fig. 2), and nighttime and morning convection over the sea to the west of the island occurs on about 1 out of 3 days in April 2002 (not shown). Assuming formation of the nocturnal offshore convection corresponds to a strong offshore flow over the sea adjacent to the western coast, nighttime offshore flow is speculated to occur on roughly 1 out of 3 days. Consequently, the offshore flow in the monthly averaged winds is weaker than that of the single case study. Moreover, when convection is involved, deep convectioninduced downdrafts yield a complex circulation pattern near the surface (Figs. 9c and 10c), which will change the monthly mean wind velocities. Nevertheless, it is evident that the offshore flow develops over the sea along the coast much earlier 
at nighttime and is stronger than land breezes caused only by radiative cooling of the land surface (Figs. 7 and 8). Therefore, it is reasonable to conclude that the afternoon and evening convection over the island frequently causes a strong offshore flow over the sea adjacent to the island during the late night and early morning.

Houze et al. (1981) reported an extremely regular genesis of nocturnal convection near the coast in northwestern Borneo (Kalimantan) and propagating offshore in the morning. They noted that the diurnal evolution and movement of the precipitation systems in northwestern Borneo are controlled by thermally- and topographically-induced diurnal changes in the boundary-layer flow. However, as pointed out by Mapes et al. (2003b), the observed diurnal cycle of winds at the northwestern Borneo coast (Fig. 8 of Houze et al. 1981) show that at no altitude does the coastal wind have a seaward component by 0200 LT, when the nocturnal convection over the sea near the coast is initiated. In the present study, the surface winds observed on the western coast of the island at Siantan also show that offshore surface winds do not occur during nighttime (Fig. 5). Moreover, the results from the numerical experiments also show that strong offshore surface winds at the western Kalimantan coast do not occur during nighttime, when the strong offshore flow occurs over the sea, and the nocturnal convection offshore near the coast is initiated (Figs. 8 and 10). Both the periods during December in the study of Houze et al. (1981) and during April in the present study are in the rainy season of the region. The observed and modelsimulated diurnal changes of surface winds at the island's western coast in the present study are similar to those observed at the northwestern Borneo coast. Occasionally, although the results from observations show weak surface winds on the coastal land of the island, a strong offshore flow over the sea adjacent to the western coast is observed in the early morning by the QuikSCAT satellite (Fig. $6)$. The results from the numerical experiments revealed that the offshore flow is induced mainly by a rapid drop in temperature in the lower atmosphere associated with afternoon and evening convection over the island, rather than primarily by nighttime radiative cooling of the land surface. The satellite observed and the model-simulated nighttime offshore surface winds over the sea adjacent to the western coast of the island are even stronger than the daytime sea breezes. The strong offshore flow creates an intensive convergence of low-level wind along its leading edge over the sea offshore near the coast, and often triggers convection offshore of the western coast at late night, as indicated by the infrared images from the GMS satellite shown in Section 2. Thus, it is reasonable to conclude that the nighttime strong offshore flow over the sea adjacent to the western coast derived principally from convection that developed over the island earlier in the afternoon and evening plays an important role in the formation of the nocturnal convection offshore from the western Kalimantan coast.

Similar to the western coast of the island, convection offshore of northwestern Kalimantan (Borneo) occurs frequently at late night and in the early morning (Fig. 2). An offshore flow is also observed over the sea adjacent to the northwestern Kalimantan coast by the QuikSCAT satellite in the early morning (Fig. 6). In the present case study, the occurrence of the offshore flow and convection over the sea along the coast at northwestern Kalimantan in the early morning are later than at the western coast. The offshore flow, the convection over the sea along the northwestern Kalimantan coast that is observed at late night and in the morning in the GMS IR images are simulated well by the model simulations (Fig. 9). As mentioned previously, the explanation based on land breeze mechanism as proposed by Houze et al. (1981) does not adequately explain the offshore convection. The mechanism proposed in the present study provides a reasonable explanation for the offshore convection at late night and in the early morning at the northwestern Kalimantan coast. In Fig. 11 of Houze et al. (1981), dissipating convection is observed over the mountainous areas of the island when the nocturnal convection near the coast in northwestern Kalimantan (Borneo) occurred at 0200 LT in their results from radar observations. The convection over the island may cause a temperature contrast between the land and the sea with lower temperatures located on the island, which in turn induces an offshore flow over the sea adjacent to the coast. Thus, the convection that developed over the island earlier in the afternoon and evening is the likely cause of the nocturnal convection over the sea offshore of northwestern Kalimantan.

\section{Summary and concluding remarks}

Precipitation measurements from the TRMM satellite indicated that rainfall over Kalimantan (Borneo) Island occurs mostly in the afternoon 
and evening along the coast of the island, and at night and in the early morning over the plains in the central regions of the island and over the sea adjacent to the coast. The infrared images from the GMS satellite during the rainy season of the region also show a regular occurrence of afternoon and evening convection over the island along the coast, and nighttime and morning convection over the sea adjacent to the island.

In this study, surface meteorological observations and numerical experiments with a mesoscale model were performed to investigate the diurnal cycle of convection over western Kalimantan Island and the adjacent seas. The results from surface meteorological observations on the western coast at Siantan showed that intense shortwave radiation is observed on most days. The shortwave radiation is intense even on days with heavy rain, since rainfall over the western coast of the island occurs mostly in the late afternoon and evening. Consequently, the diurnal changes in surface air temperature are pronounced, sea breezes are evident during 1100-1800 LT, and land breezes prevail during 0700-0900 LT. Occasionally, a strong offshore flow is observed by the QuikSCAT satellite over the sea adjacent to the western coast of the island in the early morning, with calm surface winds on the coastal land.

Model simulations for a 1-month period during the rainy season of the region successfully replicated the main features of the observed regional distribution and diurnal variation of surface winds and convection over western Kalimantan Island and the adjacent seas. The results showed that convections develop across a wide area along the western coast of the island at similar times in the late afternoon with the penetration of the sea breeze. The convections cause a rapid drop in temperature in the lower atmosphere in the evening, which produces a temperature contrast between the land and the sea with lower temperatures occurring over the island. In response to the temperature differences, a strong offshore flow occurs over the sea adjacent to the western coast of the island beginning before midnight. The offshore flow creates an intensive wind convergence at the low-levels along its leading edge, and initiates convection over the sea offshore from the western coast at nighttime. The results of this study suggest that the strong offshore flow over the sea adjacent to the western coast derived principally from convections that developed earlier in the afternoon and evening over the island plays an important role in the formation of the nocturnal convection and rainfall over the sea in the vicinity of western Kalimantan Island.

\section{Acknowledgments}

We acknowledge the insightful comments and suggestions from the anonymous reviewers. We are deeply grateful to Dr. Dennis G. Dye of the Frontier Research Center for Global Change, JAMSTEC, Japan, and to Messrs Suwarti, Urip Haryoko and Yunus, the Meteorological and Geophysical Agency of Indonesia (BMG), Indonesia, for their invaluable comments and support on this study.

\section{References}

Bayong, T. and L.D. Zadrach, 1996: The impact of El Niño on season in the Indonesian monsoon region. Proc. of Int. Workshop on the Climate System of Monsoon Asia, Kyoto, Japan, 263-266.

Carbone, R.E, W.A. Cooper, and W.-C. Lee, 1995: Forcing of flow reversal along the windward slopes of Hawaii. Mon. Wea. Rev., 123, 3466-3480.

Chen, Y.L. and A.J. Nash, 1994: Diurnal variation of surface airflow and rainfall frequencies of the Island of Hawaii. Mon. Wea. Rev., 122, 34-56.

Dudhia, J., 1993: A nonhydrostatic version of the Penn State-NCAR mesoscale model validation tests and simulation of a cyclone and cold front. Mon. Wea. Rev., 121, 1493-1513.

Feng, J. and Y.-L. Chen, 2001: Numerical simulations of airflow and cloud distributions over the windward side of the island of Hawaii. Part II: Nocturnal flow regime. Mon. Wea. Rev., 129, 1135-1147.

Hong, S.-Y. and H.-L. Pan, 1996: Nonlocal boundary layer vertical diffusion in a medium-range forecast model. Mon. Wea. Rev., 124, 2322-2339.

Houze, R.A., Jr., S.G. Geotis, F.D. Marks Jr., and A.K. West, 1981: Winter monsoon convection in the vicinity of north Borneo. Part I: Structure and time variation of the clouds and precipitation. Mon. Wea. Rev., 109, 1595-1614.

Hsu, S.-A., 1970: Coastal air-circulation system: observations and empirical model. Mon. Wea. Rev., 98, 487-509.

Ichikawa, H. and T. Yasunari, 2006: Time-space characteristics of diurnal rainfall over Borneo and surrounding oceans as observed by TRMM-PR. J. Climate, 19, 1238-1260.

Iguchi, T., T. Kozu, R. Meneghini, J. Awaka, and K. Okamoto, 2000: Rain-profiling algorithm for the TRMM precipitation radar. J. Appl. Meteor., 39, 2038-2052.

Mapes, B.E., T.T. Warner, M. Xu, and A.J. Negri, 2003a: Diurnal patterns of rainfall in northwestern 
South American. Part I: Observations and context. Mon. Wea. Rev., 131, 799-812.

Mapes, B.E., T.T. Warner, and M. Xu, 2003b: Diurnal patterns of rainfall in northwestern south America. Part III: Diurnal gravity waves and nocturnal convection offshore. Mon. Wea. Rev., 131, 830844.

Meyer, J.H., 1971: Radar observations of land breeze fronts. J. Appl. Meteor., 10, 1224-1232.

Mori, S., J.-I. Hamada, Y.I. Tauhid, M.D. Yamanaka, N. Okamoto, F. Murata, N. Sakurai, H. Hashiguchi, and T. Sribimawati, 2004: Diurnal land-sea rainfall peak migration over Sumatera Island, Indonesian maritime continent observed by TRMM satellite and intensive rawinsonde soundings. Mon. Wea. Rev., 132, 2021-2039.

Murakami, M., 1983: Analysis of the deep convective activity over the western Pacific and southeast Asia. J. Meteor. Soc. Japan, 61, 60-75.

Neale, R. and J. Slingo, 2003: The maritime continent and its role in the global climate: a GCM study. J. Climate, 16, 834-848.

Nitta, T. and S. Sekine, 1994: Diurnal variation of convective activity over the tropical western Pacific, J. Meteor. Soc. Japan, 72, 627-641.

Ohsawa, T., H. Ueda, T. Hayashi, A. Watanabe, and J.
Matsumoto, 2001: Diurnal variations of convective activity and rainfall in tropical Asia. J. Meteor. Soc. Japan, 79, 333-352.

Oki, T. and K. Mushiake, 1994: Seasonal change of the diurnal cycle of precipitation over Japan and Malaysia. J. Appl. Meteor., 33, 1445-1463.

Pielke, R.A., 1974: A three-dimensional numerical model of the sea breezes over south Florida. Mon. Wea. Rev., 102, 115-139.

Ramage, C.S., 1968: Role of a tropical Maritime Continent in the atmospheric circulation. Mon. Wea. Rev., 96, 365-370.

Saito, K., T. Keenan, G. Holland, and K. Puri, 2001: Numerical simulation of the diurnal evolution of tropical island convection over the Maritime Continent. Mon. Wea. Rev., 129, 378-400.

Simpson, J.E., 1994: Sea Breeze and Local Winds. Cambridge University Press, 234 pp.

Tao, W.-K. and J. Simpson, 1993: Goddard cumulus ensemble model. Part I: Model description. Terr. Atmos. Oceanic Sci., 4, 35-72.

Wu, P., J. Hamada, S. Mori, Y.I. Tauhid, M.D. Yamanaka, and F. Kimura, 2003: Diurnal variation of precipitable water over a mountainous area of Sumatra Island. J. Appl. Meteor., 42, 1107 -1115 . 